\title{
Prosumption in the Public Administration Sector
}

\author{
A. JAKIMOWICZ ${ }^{a}$ AND D. RzECZKOWSKI ${ }^{b}$ \\ ${ }^{a}$ Institute of Economics, Polish Academy of Sciences, \\ Palace of Culture and Science, pl. Defilad 1, PL-00901 Warsaw, Poland \\ ${ }^{b}$ Department of Quantitative Methods, Faculty of Economic Sciences, University of Warmia and Mazury in Olsztyn, \\ M. Oczapowskiego 4, PL-10719 Olsztyn, Poland
}

\begin{abstract}
The aim of this article is to examine the possibility of implementing the rules of prosumption in the public administration sector in Poland. The level of development of the Polish e-Government system is far from satisfactory, taking into consideration comparatively narrow (regarding both type and range) set of public services provided on-line. A comprehensive method of public administration sector evaluation has not been worked out yet on the level of communes, though it is very useful because of the greatest innovative potential which has not been used so far. An assessment of a relatively deteriorating indicator of innovation in the public administration sector in Poland is impossible without going to the local level and analysing the situation in certain voivodeships, especially in the communes which are the main units of the local government. Prosumption is the main idea of a new economic school called wikinomics, it means blurring the difference between the producer or a service provider and the customer by including the latter to the processes of production of goods or supplying services. According to the article, prosumption in the public administration sector can be used in two ways. Firstly, it should be known to what extent internet sites of commune offices can be transformed into social innovative platforms which could show natural creativity of customers. Secondly, it is important to determine whether the main principles of prosumption, such as getting rid of control, peering and sharing the results, can be used in practical work of commune offices. This article is focused on the research of web pages issued by the local authorities. The possibility to use web pages as platforms to provide public service on-line is evaluated. Besides, the correspondence analysis was introduced, which helped to identify the innovative potential in the public administration sector and evaluate it paying special attention to the processes of prosumption. A rational expectations hypothesis allowed to explain the process of the appearance of systematic errors in interaction between a citizen and an official. It appeared that systematic errors result in perception gaps. Prosumption is the most successful mechanism for reduction of perception gaps.
\end{abstract}

DOI: $10.12693 /$ APhysPolA.129.1011

PACS/topics: 89.65.Gh, 89.65.-s, 89.75.Fb

\section{Introduction}

Nowadays e-Government system is an innovative online platform used more and more often to provide services by the public administration sector [1]. Poland has a surprisingly low position in the international, biannual UN ranking showing the development of the sector eGovernment in 190 countries. Observation of Poland's position in this ranking between 2008 and 2014, both in terms of the value of the E-Government Development Index, as well as the changes in its components, indicate a relative lack of development in public administration, which is considered as one of the most important sectors in the entire economy [2-5]. Our article demonstrates that this challenge can be met in the public administration sector through the implementation of wikinomics and macrowikinomics, i.e. principles combining a global e-Government approach with local solutions. The main aim of this article is to identify the innovation potential of the public administration sector in the view of the UN e-Government concept illustrated by the example of the Warmia and Mazury in 2009-2015. It is a prerequisite for the implementation of prosumption in the public administration sector.

Within the concept of e-Government all public services can be divided into four categories: government to citizens $(\mathrm{G} 2 \mathrm{C})$, government to businesses (G2B), govern- ment to employees (G2E), and government to government (G2G) [6]. The concept of development of the public administration presented in this article is not limited to e-Government, but takes into consideration the basic postulates of wikinomics and macrowikinomics, which involve the inclusion of prosumption into the public administration sector. This results in the highlighted role of the society in the creation of public services, therefore G2G sector may be omitted. This means that the public administration system is considered here as a bipartite graph. The set of nodes is divided into two disjoint and non-empty subsets created by the municipal public administration offices and their customers, which include residents, the business sector and employees. Each edge has an ending point located in a subset of offices and one ending point located at a subset of the customers and thus no edge can connect points belonging to the same subset. The network approach is being increasingly used in studies of public administration [7].

Figure 1 shows the successive stages of the proposed research method. Wikinomics, macrowikinomics, and eGovernment emphasize the importance of prosumption in the public sector, which actually signifies involving the entire society in the process of designing, implementation and delivery of public services. The main requirement necessary to achieve this objective is to include municipal 


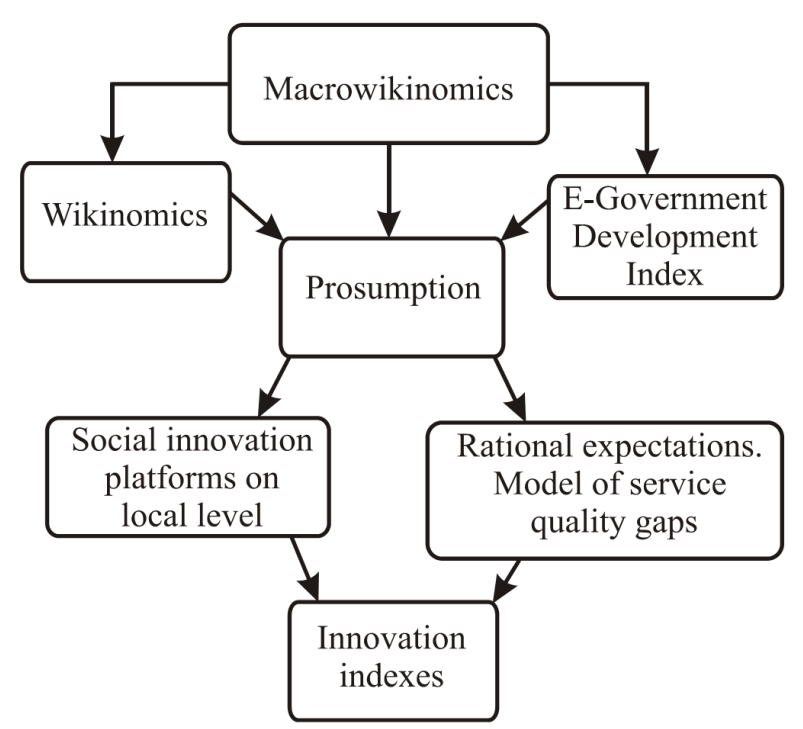

Fig. 1. Schematic diagram of the research procedure aimed at the inclusion of prosumption into public administration and consequent development of innovation indexes for this sector of the economy.

public administration offices and transform their websites into the seeds of social innovation platforms. The rationality of such actions should be monitored, which is possible owing to the model of perception gaps that points to differences between the services expected and perceived. The final step of the research procedure is the development of guidelines for innovation indexes in the public sector and this study presents some suggestions in this regard.

\section{Wikinomics and macrowikinomics}

Wikinomics was created by Tapscott and Williams, who enucleated how synergic effects - resulting from massive and spontaneous cooperation of people, supported by the use of information and communication technologies (ICT) based on open source software may contribute to the development of markets and economies [8]. The development of modern information technology forces the necessity of global actions not only in the private sector but also in the public sector. One example of such global action in public sector is the UN concept of e-Government. According to wikinomics economic processes should be defined as activities based on five basic principles: proactive fulfillment of the participant's needs, elimination of control, providing tools for the consumers, arranging an appropriate context, partnership and sharing.

A new form of management, which is postulated by wikinomics, is based on seven foundations of global cooperation that are increasingly transforming traditional patterns of business strategies. These are: the peer pioneers, ideagoras, the prosumers, the New Alexandrians, platforms for participation, the global plant floor, and the wiki workplace.
Macrowikinomics expands the notions of prosumption and participation platforms to the macroeconomic level and includes them in the public administration sector [9]. In this way, the transformation process of websites of municipal public administration into social innovation platforms, which are supposed to be used for the presentation of various achievements of society, is initiated. In other words, the implementation of the principles of prosumption in the public administration sector in Poland requires simultaneous action in two directions: the transformation of websites of municipalities into social participation platforms and building social interest in prosumptive attitudes. However, these activities must be preceded by the determination of the actual condition of these two areas, which will be the starting point of change and which will assess - by comparison with the assumed target - the scope of work needed to be done.

\section{Evaluation of the quality of websites of municipal public administration}

Implementation of the wikinomic postulates in the public sector must be preceded by an assessment of the quality of existing websites of communes. This will allow to measure the differences between the actual situation and the requirements that the websites should meet in order to be regarded as social innovation platforms. The study used communes' websites which play a major part of the Polish e-Government system, to measure the quality of social participation platforms. The evaluation of communes' websites in the Warmia and Mazury has been done in accordance with the following standards [10-14]:

- WAES — Website Attribute Evaluation System.

- A comprehensive evaluation method measuring the quality of websites.

- The World Wide Web Consortium (W3C).

These criteria take into account the guidelines contained in the Regulation of the Council of Ministers of April 12th, 2012 regarding National Interoperability Framework, which enumerate minimal requirements for public records and exchange of information in electronic form and ICT systems.

In the years 2009, 2012, and 2015 the websites of communes were evaluated according to the criteria of functionality presented in Table I. According to WAES the evaluation of website functionality is performed based on a binary method. If the presence of a given feature is confirmed then one point is given, otherwise zero. The functionality index is defined as the sum of points obtained by each of the functionalities. Figure 2 presents a collective comparison of abundance indicators of communes' websites in 2009, 2012, and 2015, on the basis of criteria A01-A16. Abundance indicators are understood as a percentage of municipalities of Warmia and Mazury, 
TABLE I multidimensional methods used for testing co-occurrence.

Criteria for assessing the functionality of websites in the years 2009, 2012, and 2015 .

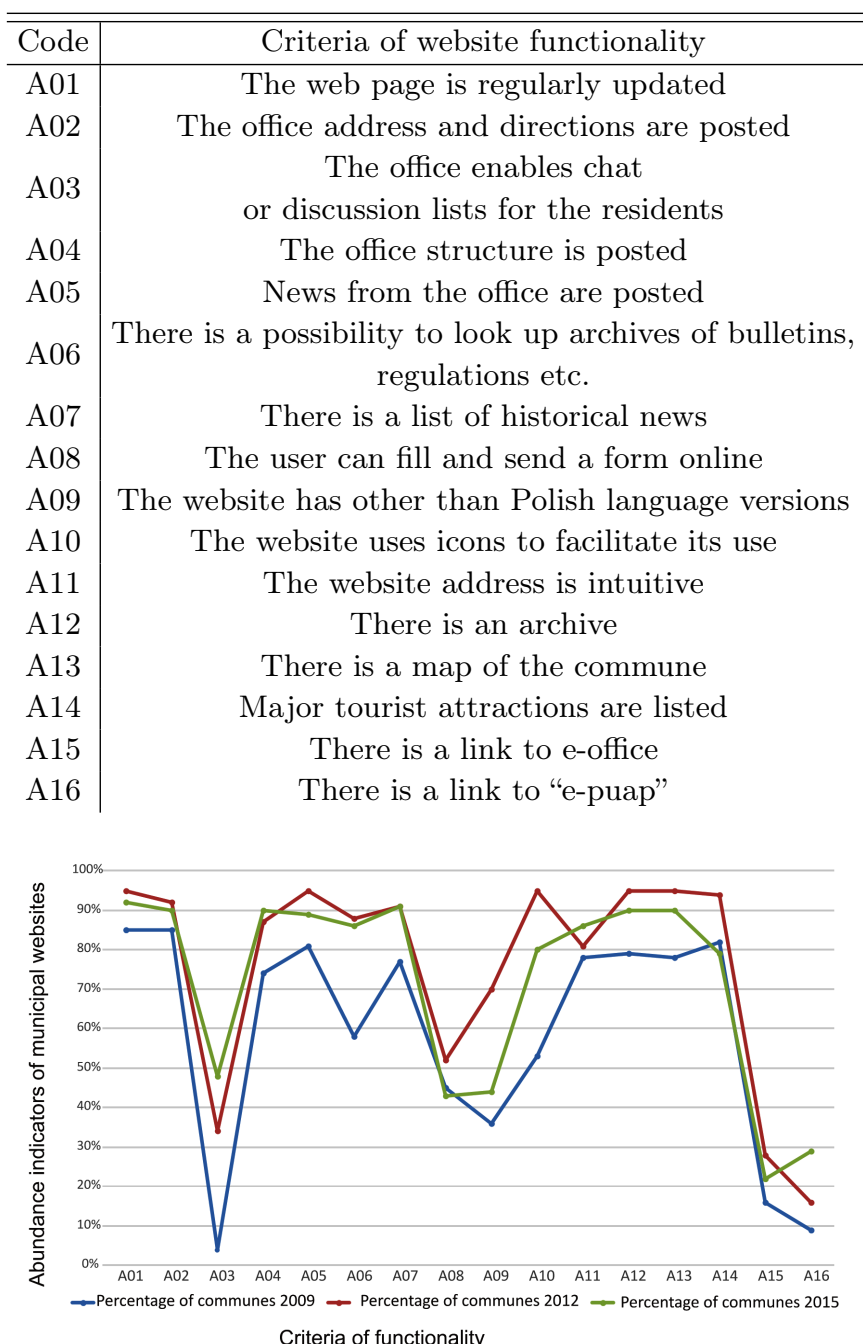

Fig. 2. Abundance indicators of municipal websites in 2009, 2012, and 2015, based on criteria of functionality A01-A16.

with websites that meet certain criteria. These indicators show a large fluctuation, however some progress can be noticed.

In future, more detailed studies should include the content of communes' websites, especially the public information bulletins [15]. They contain the exact characteristics of the specific public services and sometimes even special forms to facilitate customer access to these services.

\section{Correspondence analysis in assessing the prosumptive potential of innovation}

Correspondence analysis is a descriptive and exploratory analysis technique of binomial and multi-way tables containing indicated measures characterizing the relationship between the columns and rows. It belongs to
The focus is placed on the relationship between variables or objects. The aim of correspondence analysis is to replicate the distance between the points representing the rows or columns from a multivariate contingency table to a space of fewer dimensions. Directions of successive axes (dimensions) are determined so that the following dimensions explain the diminishing part of the total value of inertia. The number of dimensions is fixed arbitrarily. Correspondence analysis has adopted a number of concepts from the field of mechanics, although it gave them a slightly different, however intuitive, meaning which is in line with the original theory known from physics. Therefore, we come across notions such as mass, inertia or centre of mass [16-21].

\subsection{Prosumption in public administration survey}

The improvement process of the e-Government sector involves the evaluation of the quality of services provided to residents, employees and business. Contemporary definitions used in public administration assume that all office tasks can be defined as a service. The services provided by the public administration are characterized by a certain inequality of the parties involved. The service provider has a high level of competence, the customer, however, often does not know or does not understand the law. Therefore, the service recipient needs to trust the service provider. In addition, the recipient wants to participate in the service creation, which is the practical implementation of one of the basic ideas of wikinomics - prosumption. Improvement of the public officer-customer relationship is possible only when, service recipients' knowledge, experience, creativity and expectations regarding the service are used as the basis of the innovation potential.

In 2015 an anonymous survey entitled Prosumption in the public administration was conducted in Warmia and Mazury. The surveys presented opinions of the individuals regarding the services provided by the public administration. Data was collected using an auditorium technique and using face to face method. The data sample included 1812 customers of municipal public administration offices, who were residents of Warmia and Mazury in the probed year. These individuals belong to at least one of the following groups: Polish citizens, employees or entrepreneurs. Therefore, the study included relations G2C (government to citizens), G2E (government to employees), and G2B (government to businesses). The data sample was collected by a quota method, where the layers represented the population of the province counties.

\subsection{The hypothesis of rational expectations and interpersonal communication processes}

According to the hypothesis of rational expectations formulated by Muth, rational subjects, in this case the employees of public administration institutions and their customers, should shape their expectations in order to minimize systematic errors. The condition of rationality 
is determined by the subjective expectations regarding public administration services compliant with a relevant economic theory $[22,23]$. The proper theoretical basis for public service delivery system is the model of perception gaps which indicate significant gaps occurring between expectations and the actual situation. The gap which is the most important and the most difficult to diagnose is the difference between the service expected and perceived [24-32]. The occurrence of these discrepancies is related to the irrationality of the system of public services. Reduction or complete elimination of the gap and in consequence grounding the system of public services on rational conditions, requires diagnosis and elimination of the sources of irrationality. This is a prerequisite for the implementation of prosumption in the public sector. Therefore, the interpersonal communication processes between customers and officials should be carefully investigated.

\section{TABLE II}

Combination of categories of nervous tensions in customer-public officer contact with age and gender combination.

\begin{tabular}{c|c|c|c|c|c|c|c}
\hline \hline $\begin{array}{c}\text { Age groups: } \\
\text { women (W1-W5) } \\
\text { men (M1-M5) }\end{array}$ & B01 & B02 & B03 & B04 & B05 & B06 \\
\hline 18-20 & W1 & 6 & 13 & 17 & 23 & 49 & 28 \\
$21-35$ & W2 & 28 & 168 & 175 & 212 & 291 & 321 \\
$36-45$ & W3 & 1 & 31 & 35 & 24 & 29 & 41 \\
$46-60$ & W4 & 4 & 32 & 34 & 20 & 25 & 34 \\
Up 60 & W5 & 9 & 15 & 15 & 17 & 20 & 19 \\
$18-20$ & M1 & 20 & 45 & 19 & 20 & 38 & 29 \\
$21-35$ & M2 & 103 & 242 & 326 & 187 & 278 & 295 \\
$36-45$ & M3 & 13 & 41 & 64 & 50 & 63 & 55 \\
$46-60$ & M4 & 10 & 33 & 22 & 21 & 39 & 46 \\
Up 60 & M5 & 6 & 12 & 9 & 11 & 14 & 11
\end{tabular}

During the survey, the customers were asked to evaluate the sources of irrationality in interpersonal contacts with the officials. On the basis of sociological and economical criteria, the following issues were proposed for further consideration:

B01 - addressing the customer by his/her surname,

B02 - rude interrupting,

B03 - assigning hidden, bad intentions to the customer,

B04 - violent opposition, rude denial,

B05 - disrespectful facial mimic,

B06 - showing irritation at words or the presence of the customer.

Customer responses are presented in Table II.

Correspondence analysis has been used to research the rationality of the system of public services. The aim of correspondence analysis is to replicate the distance between the points representing the rows or columns from a multivariate contingency table to a space of two dimensions or three dimensions. It does not require any specific assumptions regarding the data. Gourieroux and
Pradel proposed a method for testing the rationality of expectations, which is somewhat similar to correspondence analysis, because in both cases contingency tables are the starting point $[33,34]$. The idea of using biplots to study rationality has great cognitive potential, though as yet, it is rarely used in economics [35].

Verification of the assumptions regarding the customer nervous tension caused by an official and dependent on the age of the customer requires the assessment of the truthfulness of the following hypotheses:

$H_{0}$ : customer's nervous tension caused by the public officer does not depend on the gender and age of the customer,

$H_{1}$ : customer's nervous tension caused by the public officer depends on the gender and age of the customer.

The total of assumptions and calculations essential for the verification of the hypotheses above, such as $\chi^{2}$, critical area, level of significance, critical value have been summarized in Table III. According to the calculations contained in Table III, the null hypothesis should be rejected in favour of the alternative hypothesis, which means that the customers' nervous tension caused by the public officer depends on the age and sex of the customer.

TABLE III

Calculations necessary to verify the hypothesis regarding the codependence of nervous tension caused by the public official and age and gender.

\begin{tabular}{c|c}
\hline \hline \multicolumn{2}{c}{ Independence test for a multivariate array - Table II } \\
\hline value of $\chi^{2}$ & 177.25 \\
critical area & right-hand area \\
level of significance & 0.05 \\
critical value & $\chi^{2}(0.05 ; 45)=61.65$ \\
decision & null hypothesis is false
\end{tabular}

In order to determine what are the sources of nervous tensions of the customer resulting from the customerpublic officer relation, depending on the age group of the customer, correspondence analysis should be applied to the data in Table II. Table IV shows the singular values and eigenvalues of matrix correspondence, as well as the percentages of inertia with its cumulative values and the distances $\chi^{2}$. The first dimension reproduces $58.2 \%$ of the total inertia and the second $24.3 \%$. Two dimensions were selected for further analysis, which gives a total of $82.5 \%$ of inertia.

TABLE IV

Characteristics of the correspondence matrix (for the data from Table II).

\begin{tabular}{c|c|c|c|c|c}
\hline \hline $\begin{array}{c}\text { No. } \\
\text { of } \\
\text { dim. }\end{array}$ & $\begin{array}{c}\text { Singular } \\
\text { value }\end{array}$ & Eigenvalue & $\begin{array}{c}\text { Percent } \\
\text { of inertia }\end{array}$ & $\begin{array}{c}\text { Cumulated } \\
\text { percent }\end{array}$ & $\begin{array}{c}\text { Chi-square } \\
\text { distance } \\
\left(\chi^{2}\right)\end{array}$ \\
\hline 1 & 0.163509 & 0.026735 & 58.19280 & 58.1928 & 103.1439 \\
2 & 0.105692 & 0.011171 & 24.31494 & 82.5077 & 43.0971 \\
3 & 0.075348 & 0.005677 & 12.35741 & 94.8652 & 21.9029 \\
4 & 0.035040 & 0.001228 & 2.67255 & 97.5377 & 4.7370
\end{tabular}


Table $\mathrm{V}$ shows respectively the coordinates of the lines (age groups by gender) and columns (customers' nervous tension caused by a public officer during an official visit at the public office) together with the statistics of the quality of the solution. This information is necessary to provide adequate maps of correspondence indicating the co-occurrence of customers' nervous tension which was caused by an officer during a visit at a public office and their age and gender.

TABLE V

Correspondence analysis: customer's nervous tension caused by the public officer during a visit at the office and their age and gender groups.

\begin{tabular}{|c|c|c|c|c|c|c|c|c|c|}
\hline \multicolumn{10}{|c|}{ Coordinates of columns and input to inertia } \\
\hline \multirow[b]{2}{*}{ Col. } & \multicolumn{2}{|c|}{ Dimension } & \multirow[b]{2}{*}{ Mass } & \multirow[b]{2}{*}{ Quality } & \multirow{2}{*}{$\begin{array}{c}\text { Relative } \\
\text { inertia }\end{array}$} & \multicolumn{2}{|c|}{ Inertia } & \multicolumn{2}{|c|}{ Contributions } \\
\hline & Axis 1 & Axis 2 & & & & Axis 1 & Axis 2 & Axis 1 & Axis 2 \\
\hline B01 & 0.474 & -0.236 & 0.052 & 0.962 & 0.329 & 0.435 & 0.258 & 0.771 & 0.191 \\
\hline B02 & 0.131 & -0.031 & 0.164 & 0.488 & 0.132 & 0.105 & 0.014 & 0.462 & 0.026 \\
\hline B03 & 0.140 & 0.181 & 0.186 & 0.938 & 0.226 & 0.135 & 0.547 & 0.349 & 0.589 \\
\hline B04 & -0.129 & -0.005 & 0.152 & 0.699 & 0.079 & 0.094 & 0.000 & 0.697 & 0.001 \\
\hline B05 & -0.111 & -0.093 & 0.219 & 0.782 & 0.128 & 0.100 & 0.171 & 0.457 & 0.326 \\
\hline B06 & -0.123 & 0.022 & 0.228 & 0.727 & 0.107 & 0.130 & 0.010 & 0.705 & 0.022 \\
\hline \multicolumn{10}{|c|}{ Coordinates of rows and input to inertia } \\
\hline & \multicolumn{2}{|c|}{ Dimension } & \multirow[b]{2}{*}{ Mass } & \multirow[b]{2}{*}{ Quality } & \multirow{2}{*}{$\begin{array}{c}\text { Relative } \\
\text { inertia }\end{array}$} & \multicolumn{2}{|c|}{ Inertia } & \multicolumn{2}{|c|}{ Contributions } \\
\hline Rows & Axis 1 & Axis 2 & & & & Axis 1 & Axis 2 & Axis 1 & Axis 2 \\
\hline W1 & -0.221 & -0.197 & 0.035 & 0.608 & 0.111 & 0.065 & 0.122 & 0.340 & 0.268 \\
\hline $\mathrm{W} 2$ & -0.202 & -0.011 & 0.310 & 0.985 & 0.280 & 0.472 & 0.004 & 0.982 & 0.003 \\
\hline W3 & -0.074 & 0.188 & 0.042 & 0.672 & 0.055 & 0.009 & 0.132 & 0.090 & 0.582 \\
\hline W4 & 0.053 & 0.160 & 0.039 & 0.551 & 0.044 & 0.004 & 0.089 & 0.054 & 0.497 \\
\hline W5 & 0.101 & -0.141 & 0.025 & 0.621 & 0.026 & 0.009 & 0.044 & 0.212 & 0.409 \\
\hline M1 & 0.274 & -0.315 & 0.044 & 0.895 & 0.188 & 0.124 & 0.394 & 0.385 & 0.510 \\
\hline M2 & 0.148 & 0.045 & 0.371 & 0.946 & 0.205 & 0.306 & 0.066 & 0.867 & 0.079 \\
\hline M3 & 0.006 & 0.076 & 0.074 & 0.289 & 0.033 & 0.000 & 0.039 & 0.002 & 0.288 \\
\hline M4 & -0.020 & -0.119 & 0.044 & 0.396 & 0.035 & 0.001 & 0.056 & 0.011 & 0.385 \\
\hline M5 & 0.131 & -0.193 & 0.016 & 0.816 & 0.024 & 0.010 & 0.054 & 0.257 & 0.559 \\
\hline
\end{tabular}

The results of correspondence analysis have been shown in a two-dimensional space in a form of a biplot [36-41]. Figure 3 shows the sources of irrationality as the relationship between customer's nervous tension caused by a public officer during an office visit and the age and gender of customers. The degree of rationality is often influenced by such factors as gender and age of the respondents. Questions B01-B06 were formulated in such a way as to demonstrate the sources of irrationality in the system of public services provided by municipal public administration offices. Hence the origin should be treated as a standard of irrationality (the centre of mass of the tested system) specified by the customers. In this case, the smaller the distance between points B01-B06 and the standard, the greater the degree of irrationality should be attributed to them. Conversely, the larger the distance of these points from the origin, the greater the level of rationality (or the smaller level of irrationality) should be attributed to them. Thus, the distance between points B01-B06 and the average expected degree of irrationality which the customer of the public office predicts, is the measure of rationality/irrationality.
In order to better visualize the results shown in Fig. 3, points W1-W5 representing the age groups of women were connected with a green line, whereas points M1-M5 corresponding to the age groups of men were connected with a blue line. Distances from the standard of various sources of irrationality are marked by red arrows. The arrow pointing at point B01 is the longest, while the arrow pointing to B06 is the shortest. This means that the first characteristic is a much smaller source of irrationality than the second one. The set of green points W1-W5, representing the age groups of women, is shifted to the left of the blue points M1-M5 representing the age groups of men. It should be noted that in the left part of the diagram, there are three main sources of irrationality - points B04, B05, and B06. This means that in this specific study, women proved to be more sensitive than men to the given sources of irrationality. Extension of the arrow running in the direction of B05 points to $\mathrm{W} 1$, therefore young women are very sensitive to being ignored by the officials and show a strong sensitivity to this characteristic. It is worth noting that the B01 feature does not seem to be a clear source of irrationality. 


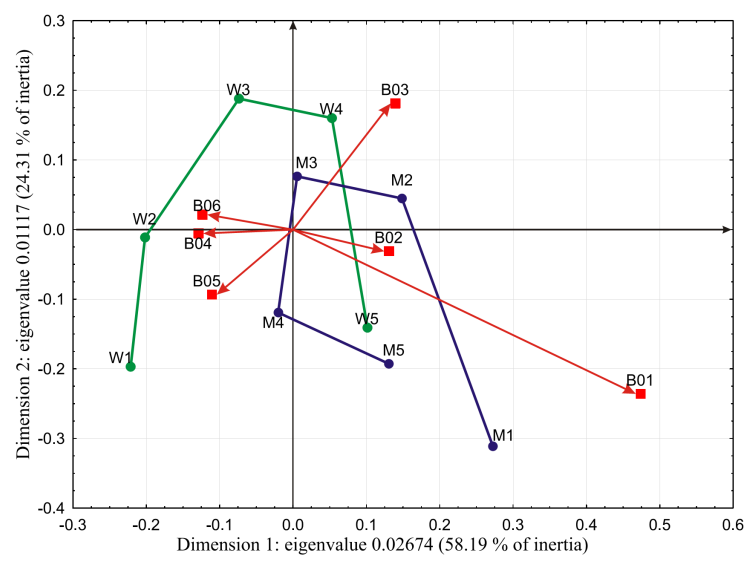

Fig. 3. Sources of irrationality and their impact on the interpersonal communication between customers and officials.

The closest to point B01 is the point M1, thus addressing to the customer by the surname may be disliked by some of the young men. Vectors B04 and B06 form very sharp angles with the vector connecting the origin and point W2, which means that women aged 21 to 35 do not like when an official opposes them and shows irritation at their statements. In Fig. 3 many other detailed dependences pointing to sociologically grounded rationality can be noticed.

\section{Potential for innovation meter in the public sector}

Research on prosumption and participation of citizens in the process of designing, implementing, and delivery of public services indicates the possibility of development of innovation indexes that could be used in the assessment of the actual state of the public administration sector. On this ground - knowing the multidimensional gap between the actual situation and the model postulated by wikinomics, macrowikinomics, the idea of e-Government and the model of perception gaps - recommendations for economic policy that include measures needed to be undertaken in order to achieve the desired goal, could be formulated. Innovation indexes measuring the innovation potential of the public administration sector should include the following elements:

- Application of sixteen criteria of website evaluation to assess the websites of communes; the evaluation was performed in a binary way by assigning a corresponding amount of points, therefore each criterion of assessment has been given a point if the criterion has been met. The selected criteria have been chosen according to the e-Government guidelines and the prosumption model.

- Comparison of the changes in communes' web sites over time. The study was conducted in 2009, 2012, and 2015, which allows communes to track changes in their communication platform and shifts in meeting given criteria for evaluation.

- The use of the hypothesis of rational expectations for identifying systematic errors in the process of interpersonal communication. These errors are an exemplification of the gaps postulated by models of service quality and are key factors in lowering of the quality of public services in the test region. It can be concluded that the degree of rationality is not only affected by the age of the respondents, but also by their gender.

- Identification of the most important principles of cooperation in the relations between the public officer and customer.

- Identification of expectations and preferences of customers, which can become a source of creativity useful in transforming communes' webpages to social innovation platforms.

\section{Conclusions}

The study indicates that the implementation of prosumptive objectives at the local level can be difficult and time consuming. Websites of municipal public administration are not quite prepared to act as social innovation platforms designed to be used to present the ideas and achievements of society. The implementation of the ideals postulated by e-Government, wikinomics, and macrowikinomics is unlikely to be possible in the near future. Nevertheless, some progress in this regard can be observed since the general trend is that the communes are trying to improve the quality of communication with customers online. The interpersonal communication between officials and the general public seems to be in a worse condition. It is a significant source of irrationality in the system of public services and it should be presumed that it is not limited only to Warmia and Mazury. The situation in this scope can be improved by training of the office staff, especially the employees who have direct contact with customers. Skills of officials must be constantly improved and include many aspects, an example of which is the specification resulting from sociological factors.

The development of new technologies and the gradual extension of the scope of services provided online will certainly serve bridging the gap between the expected and perceived service. However, IT tools will not eliminate all sources of irrationality. The practical implementation of the model of prosumption requires above all citizens' trust in the state, the citizen must be convinced that the state is acting in his or her interest. An issue for discussion is the size of state interference in the lives of citizens, employees, and entrepreneurs, as this determines the range of public services. The state, in the nature of things, is in fact a monopolist when services provided by public administration are concerned. 


\section{References}

[1] F. Bouaziz, Electron. J. e-Governm. 6, 11 (2008).

[2] United Nations E-Government Survey 2008: From EGovernment to Connected Governance, United Nations, New York 2008.

[3] United Nations E-Government Survey 2010: Leveraging E-Government at a Time of Financial and Economic Crisis, United Nations, New York 2010.

[4] United Nations E-Government Survey 2012: EGovernment for the People, United Nations, New York 2012

[5] United Nations E-Government Survey 2014: EGovernment for the Future We Want, United Nations, New York 2014.

[6] C. Blake, O. Fayomi, C. Ayo, in: Proc. 15th Europ. Conf. on e-Government, Ed. C. Adams, Academic Conferences and Publishing International Limited, Reading 2015, p. 37.

[7] Methodology of Measuring the Functioning of Public Administration Network, Eds. P. Modzelewski, K. Opolski, CeDeWu, Warszawa 2014 (in Polish).

[8] D. Tapscott, A.D. Williams, Wikinomics: How Mass Collaboration Changes Everything, Portfolio, New York 2006.

[9] D. Tapscott, A.D. Williams, Macrowikinomics: Rebooting Business and the World, Portfolio/Penguin, New York 2012.

[10] H. Marjak, Prace Naukowe, Szkoła Główna Gospodarstwa Wiejskiego, Wydział Nauk Ekonomicznych, Katedra Polityki Agrarnej i Marketingu, No. 45, 2008, p. 355 (in Polish).

[11] H. Marjak, Folia Pomeranae Universitatis Technologiae Stetinensis, Oeconomica 308, 73 (2014) (in Polish).

[12] M. Ślusarski, Infrastruktura $i$ Ekologia Terenów Wiejskich III, 109 (2012) (in Polish).

[13] M. Feltynowski, Infrastruktura i Ekologia Terenów Wiejskich II, 393 (2015).

[14] K. Zarańska, in: XVII Scientific Conference on Innovation in Management and Production Engineering, Vol. 2, Zakopane 2014, p. 902 (in Polish).

[15] D. Rzeczkowski, Innovation Potential in the Public Administration Sector, Wydawnictwo Naukowe PWN, Warszawa 2014 (in Polish).

[16] P. Bourdieu, Distinction: A Social Critique of the Judgement of Taste, Harvard University Press, Cambridge 1996 .

[17] M. Greenacre, Correspondence Analysis in Practice, Chapman and Hall/CRC, Boca Raton 2007.

[18] L. Lebart, A. Morineau, K.M. Warwick, Multivariate Descriptive Statistical Analysis: Correspondence Analysis and Related Techniques for Large Matrices, Wiley, New York 1984.
[19] Statistics for the 21st Century: Methodologies for Applications of the Future, Eds. C.R. Rao, G.J. Székely, A. Rényi, Marcel Dekker, New York 2000.

[20] Z. Sawiński, Application of Tables in Social Studies, Wydawnictwo IFiS PAN, Warszawa 2010 (in Polish).

[21] J. Górniak, ASK 9, 115 (2000) (in Polish).

[22] J.F. Muth, Econometrica 29, 315 (1961).

[23] E. Tomczyk, Rationality of Expectations. Methods and Analysis of Qualitative Data, Oficyna Wydawnicza SGH, Warszawa 2004 (in Polish).

[24] L. Gaster, A. Squires, J. Crawley, M. Greenwood, T. Harding, C. Hayden, P. Scrutton, Providing Quality in the Public Sector: A Practical Approach to Improving Public Services, Open University Press, Philadelphia 2003.

[25] A. Shahin, M. Samea, Business Management and Strategy 1, E2 (2010).

[26] A. Gupta, J.C. McDaniel, S.K. Herath, Managing Service Quality 15, 389 (2005).

[27] Can't Get No Satisfaction? Using a Gap Approach to Measure Service Quality, Accounts Commission for Scotland, December 1999.

[28] R. Wolniak, B. Skotnicka-Zasadzień, Zeszyty Naukowe Akademii Podlaskiej w Siedlcach, Seria: Administracja i Zarzadzanie 85, 169 (2010) (in Polish).

[29] B. Pawłowska, I. Seredocha, Prace Naukowe Akademii im. Jana Dtugosza w Częstochowie 6, 35 (2012) (in Polish).

[30] A. Parasuraman, V.A. Zeithaml, L.L. Berry, J. Market. 49, 41 (1985).

[31] A. Parasuraman, V.A. Zeithaml, L.L. Berry, J. Retail. 64, 12 (1988)

[32] K. Opolski, P. Modzelewski, Quality Management in Public Services, CeDeWu, Warszawa 2012 (in Polish).

[33] C. Gourieroux, J. Pradel, Europ. Econ. Rev. 30, 265 (1986).

[34] B. Kowalczyk, E. Tomczyk, Bank Kredyt 39, 3 (2008).

[35] S.. Lezki, S. Aydin, F. Er, Alphanum. J. 3, 59 (2015).

[36] P. Filzmoser, K. Hron, Math. Geosci. 40, 233 (2008).

[37] P. Filzmoser, K. Hron, Math. Geosci. 41, 905 (2009).

[38] P. Filzmoser, K. Hron, in: Proc. in Computational Statistics 2010, Eds. Y. Lechevallier, G. Saporta, Springer-Verlag, Berlin 2010, p. 79

[39] P. Filzmoser, K. Hron, C. Reimann, Environmetrics 20,621 (2009).

[40] P. Filzmoser, K. Hron, M. Templ, Comput. Stat. 27, 585 (2012).

[41] M. Greenacre, Biplots in Practice, Fundación BBVA, Bilbao 2010. 